\title{
Habitual Visual Acuity in Schoolchildren from Rural and Urban Regions of Allahabad
}

\author{
Article by Mohammad Junaid Siddiqui ${ }^{1}$, Imran Mehboob Baig ${ }^{2}$, Arjumand $^{3}$ \\ ${ }^{1}$ Master of Optometry, College of Health Science, University of Buraimi \\ ${ }^{2}$ M. Phil (Physiology), College of Health Science, University of Buraimi \\ ${ }^{3}$ M. Phil (Pathology), Buraimi Hospital \\ E-mail: junaidopt@gmail.com ${ }^{1}$
}

\begin{abstract}
Introduction: Visual acuity (VA) helps to appreciate the three-dimensional details of surrounding and can be used to measure the visual functions in ocular practice, especially as a screening tool in schoolchildren. Visual impairment (VI) is the major cause of morbidity in children worldwide, which can affect the learning of children globally.

Aim: Present study was aimed to use Snellen's VA chart as a screening tool to find out habitual VA and VI in schoolchildren of Allahabad.

Material \& Methods: Snellen's chart was used in 567 students belonged to 3 schools from rural and urban areas of Allahabad. The result was tabulated showing number of eyes from 6/60 to 6/6 in schoolchildren between 7 to 11 years of age.

Result: Majority of the schoolchildren (80.42\% eyes) had normal VA (6/6), while only 1 student had $V A$ of $6 / 60$ in both of his eyes (0.18\%). Both, the urban and rural schools showed a higher number for VA 6/9 in 167 eyes (14.73\%) altogether, where 91 eyes belonged to rural school and 76 eyes to urban schools. Schoolchildren from rural and urban schools showed6/12 VA in 19 and 9 eyes, respectively. No such significant difference was seen in VA of 6/18 and 6/24 for rural schoolchildren, while urban school students showed a marked distinction.

Conclusion: The investigator concluded that the identification of reduced habitual VA at an early stage will help to reduce the childhood blindness and might help to assess visual development for the children.
\end{abstract}

Keywords: Visual acuity, visual impairment, habitual visual acuity, schoolchildren, childhood blindness.

\section{Introduction}

VA is defined as the "assessment of the eye's ability to distinguish object details and shape, using the smallest identifiable object that can be seen at a specified distance, usually 20 feet" (Marsden, Stevens and Ebri, 2014). Not only, it helps to appreciate the three-dimensional details of surrounding, but also helps to measure the visual functions in ocular practice (Anstice and Thompson, 2013). It is linked with the quality of life as many of the daily functions such as mobility depends on it. It even helps the patients to live their life self-reliantly (Hochberg et al, 2012). Anstice and Thompson (2013) regarded VA measuring test, as most important tool for general visual functions, as it helps a clinician to identify the refractive errors and visual pathway associated pathologies.

Vision allows schoolchildren to capture and decode the symbolic information (letters, numbers, drawings, etc.) and it involves both far and near vision (Gene-Sampedro et al., 2016). Eyes can perceive $90 \%$ of the information of surrounded world (Pastorino and Penerini, 1998), which makes vision as the most important tool for learning, especially in school.

$\mathrm{VI}$ is the major cause of morbidity in children worldwide, where refractive error is identified as its most common cause. Whereas, in India, it is considered to be the second major cause of blindness (Dandona and Dandona, 2001). Another study had stated myopia as the most common cause of VI in children (He et al., 2007). Curable refractive errors exhibited a major share (50-72.5\%) of reduced VA in children, worldwide (Zhao et al., 2000; Maul et al., 2000). 
According to World health organization (WHO, 2012), VI is affecting the learning development of around 12 million children globally. It has further stated that there are 1.5 million blind children worldwide, out of which, two-thirds are in Africa and Asia (Gilbert \& Foster, 2001). One study reported that more than 200,000 children from India are suffering from blindness (Smith, 1995), while another study from south India also identified the prevalence of blindness in schoolchildren (Dandona et al., 1998). While, Dandona and Dandona (2001) found an increase in the number of cases for amblyopia in children in his study. Therefore, VA measurement is appreciated by all public health vision screening programs to be included for visual evaluation (Anstice and Thompson, 2013).

For this reason, present study used Snellen's VA chart as a screening tool find out habitual VA and to identify the cases of VI in schoolchildren from one of the major cities of a lower literate state of India.

\section{Material and methods}

Allahabad is one of the metropolitan cities in Uttar Pradesh state of India. The Municipal Corporation of Allahabad Metropolitan Region administers the city (District Census Handbook, 2011). Uttar Pradesh is considered to have a lower literacy rate (67.68 percent) as compared to many other states of India. (Education Status Report - Uttar Pradesh 2013)

According to District Census Handbook (2011), 24.74\% of Allahabad population represented the urban regions of district and $75.26 \%$ population of Allahabad districts belonged to rural areas. Where, the child population accounted for $10.97 \%$ of total urban population and $16.27 \%$ of the total rural population of Allahabad district. Child sex ratio in Allahabad district was 878 girls per 1000 boys for urban region and 914 girls per 1000 boys for rural region.

Out of many schools of Allahabad district Uttar Pradesh, India, three schools voluntarily agreed to participate in the study. The authorization to conduct the vision screening was taken by the principal of each school. A total number of 567 students from the schools (from the Grades 3, 4, 5 and 6), approximately between the age of 7 to 11 years were enrolled in the study. They were screened by investigator for Habitual VA, which is the VA that a person usually has with or without spectacles (Brien Holden Vision Institute, 2016). It was measured by using Snellen's VA chart. The vision screening chart was placed at a distance of $6 \mathrm{~m}$ in setting with proper daylight illumination. The height of chart was adjusted according to the general eye level of average height for participated children. Each eye was tested individually with the help of occlude. Children were asked to read the alphabets on the chart. If a child was unable to read the line completely than the last complete line was recorded as VA result and incomplete line was added to the last complete line.

The data was collected from those 3 schools and entered in MS office excel 2013 worksheet. Habitual VA was then calculated in percentage for both rural and urban schools to identify the number of cases for VI.

\section{Result}

In present study, investigator screened 1134 eyes of 567 children from three different schools (school 1, school 2 and school 3) of Allahabad district, from class 3 to 6 (including different sections from each class). School $1 \&$ school 2 belonged to urban region of Allahabad district, while school 3 belonged to rural area.

Among $\mathrm{n}=567$ students, $300(52.91 \%)$ students belonged to urban region from two schools whereas 267 (47.09\%) students belonged to one school from rural region of the Allahabad district (Figure 1). This represents an increase in registration of children in rural area.

Figure 2 is representing the gender frequency in schoolchildren where, the schools were divided in to 2 categories, urban and rural regions. Urban region of Allahabad included School 1 and School 2 while, rural category included only School 3. 


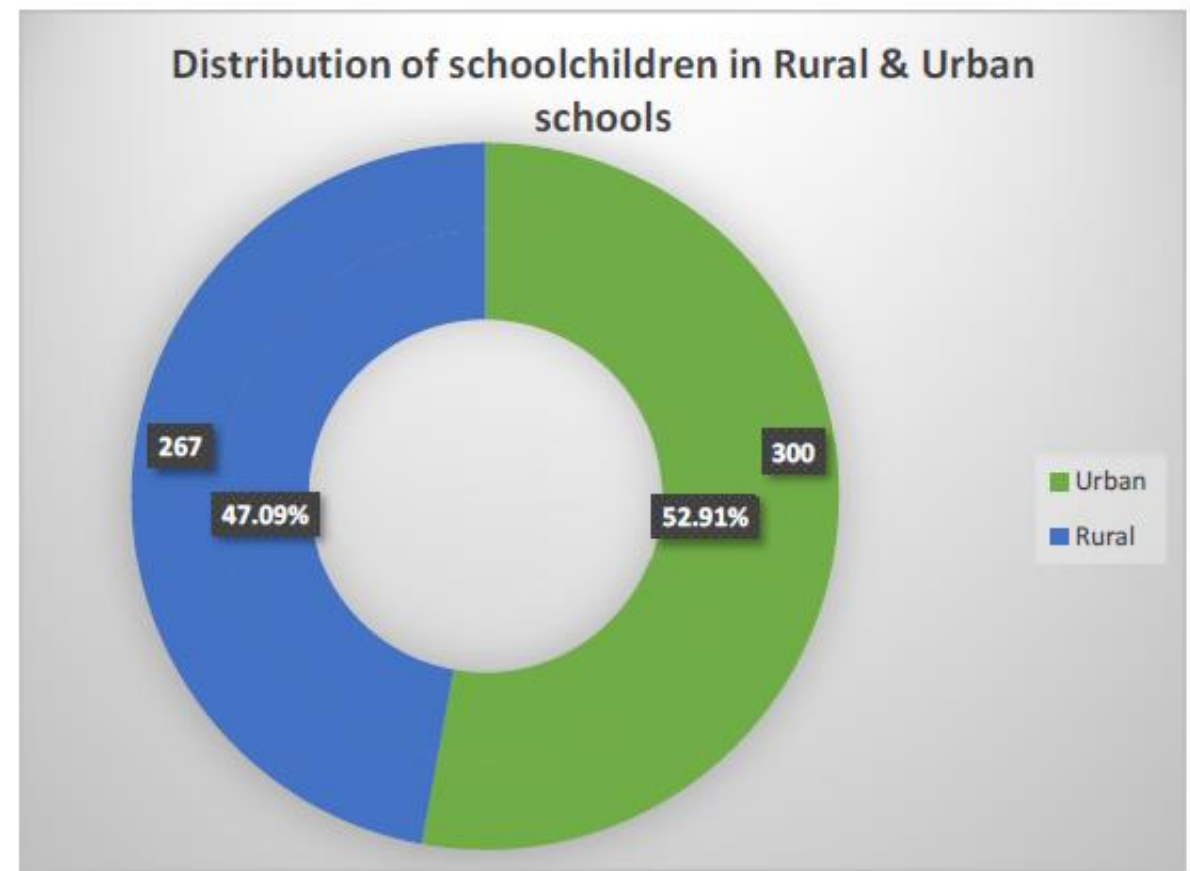

Figure 1. Distribution of schoolchildren in urban and rural schools of allahabad district

The figure is expressing that from urban schools 191 (63.67\%) and from rural school 158 (59.18\%) schoolchildren were boys. While, girls shared the same frequency of 109 from urban (36.33\%) and rural $(40.82 \%)$ schools.

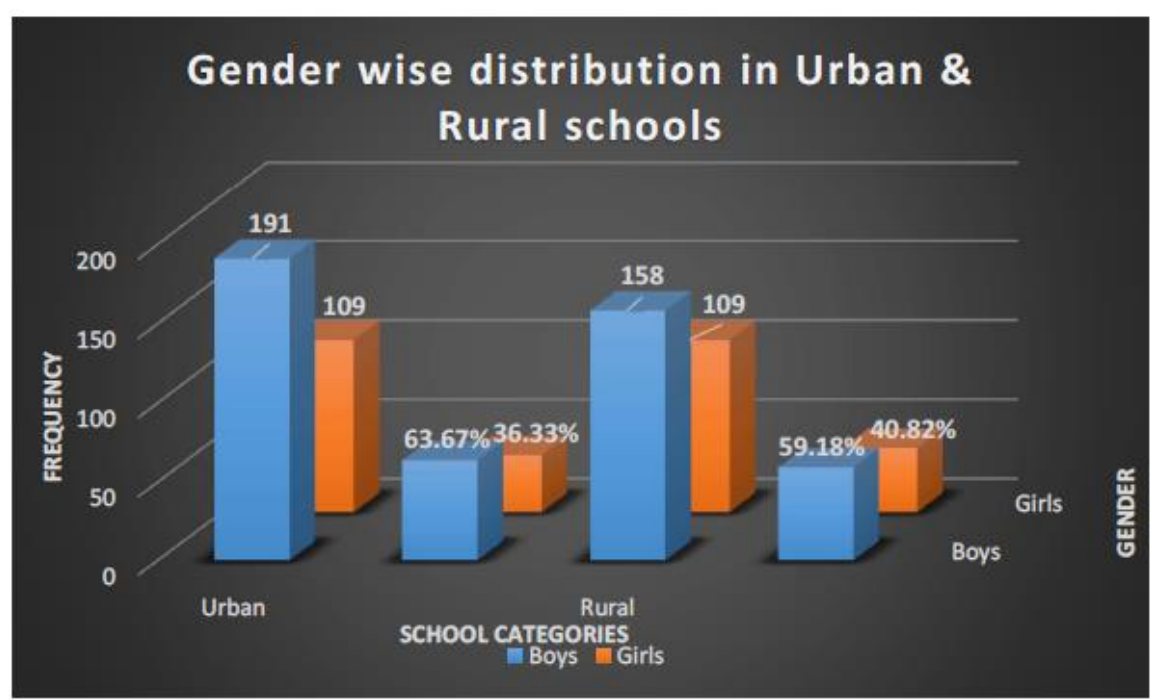

Figure 2. Gender wise distribution of Schoolchildren from urban and rural schools of Allahabad district

Table is showing the habitual VA results of 1134 eyes of schoolchildren from Allahabad, recorded by investigator. Where, majority of the schoolchildren $(80.42 \%$ eyes) had normal VA $(6 / 6)$. While, worst VA (6/60) was seen in only 1 student in both of his eyes $(0.18 \%)$, belonged to one of the urban schools. Both, the urban and rural schools showed a higher number for VA $6 / 9$ in 167 eyes $(14.73 \%)$ altogether. 
DOI: $10.21522 /$ TIJPH.2013.06.03.Art013

ISSN: $2520-3134$

Table 1. Prevalence of habitual visual acuity among rural \& urban schools of Allahabad

\begin{tabular}{|l|l|l|l|l|}
\hline \multirow{2}{*}{$\begin{array}{l}\text { VA (Snellen } \\
\text { fraction) }\end{array}$} & $\begin{array}{l}\text { Number (n) of Eyes } \\
\text { Examined }\end{array}$ & $\begin{array}{l}\text { Urban } \\
\text { Schools }\end{array}$ & Rural School eyes & \multirow{2}{*}{$\begin{array}{l}\text { Percentage } \\
\text { examined }\end{array}$} \\
\cline { 2 - 5 } & 499 & 413 & 912 & $80.42 \%$ \\
\hline $6 / 6$ & 76 & 91 & 167 & $14.73 \%$ \\
\hline $6 / 9$ & 9 & 19 & 28 & $2.47 \%$ \\
\hline $6 / 12$ & 11 & 5 & 16 & $1.41 \%$ \\
\hline $6 / 18$ & 1 & 4 & 5 & $0.44 \%$ \\
\hline $6 / 24$ & 2 & 2 & 4 & $0.35 \%$ \\
\hline $6 / 36$ & 2 & 0 & 2 & $0.18 \%$ \\
\hline $6 / 60$ & 600 & 534 & 1134 & $100 \%$ \\
\hline TOTAL & & & & \\
\hline
\end{tabular}

Out of which, 91 eyes belonged to rural school followed by urban schools (76 eyes). VA of 6/12 VA was found in 19 and 9 eyes from rural and urban schools respectively. Amazingly, there was no such difference in results for VA of 6/18 (5 eyes) and 6/24 (4 eyes) for rural school. On the other hand, results for similar VA from urban schools showed a marked difference (11 eyes for $6 / 18$ and 1 eye for 6/24). Schools from both areas shared the same result (2 eyes for each) for VA of 6/36 (0.35\%).

\section{Discussion}

The study was conducted in three different schools from Allahabad district of Uttar Pradesh, India, enrolling 567 schoolchildren from grade 3 to 6 . Visual screening was done by investigator with help of Snellen's chart. Frequency was measured for all VA results and used to find out the number of cases for VI in these school children.

A study from Kenya showed a relatively higher enrolment in rural school (91.86\%) than the urban schools $(89.97 \%)$, which is dissimilar to our study where larger number of registrations are seen for urban schools $(52.91 \%)$ than the rural school $(47.09 \%)$. It is because of including two schools from urban region in present study. This higher registration from the Kenyan study might be due to promotion of education to the Kenyan children (Mugisha, 2006).

In present study, male schoolchildren enrolled in urban and rural areas were $63.67 \%$ and $59.18 \%$ respectively, while girls' enrolment was $36.33 \%$ and $40.82 \%$, respectively. This shows a little higher registration for girls in rural area than the boys. Our result agrees, to the data presented by Ministry of Statistics \& Program Implementation (2015), government of India, for urban area where boys and girls registration were $57 \%$ and $54.6 \%$ respectively. On the other hand, registration for educational institutions for rural area showed a disparity with our result as they presented a lower rate of registration for girls (53\%) than the boys $(58.7 \%)$. This difference might be due to inclusion of higher range of age limit (5-29 years) in their study while, present study included a lower range for age (7-12 years).

Azizoğlu et al., (2017) supported our study for VA of 6/6, as he found a similar result (86.4\%) in schoolchildren. In our study, it was found in $80.42 \%$ schoolchildren. Whereas, a huge difference in result was observed between both studies for VA of 6/9. Present study showed a higher percentage (17.5\%) in comparison to his study (2.5\%). Our study also showed a little higher percentage (2.36\%) than his study $(0.5 \%)$ for VA of 6/18 or less. In one study conducted in USA, Harvey, Dobson and Miller (2006) measured a habitual VA in 1,327 schoolchildren between 5 to 16 years, whereas in our study, schoolchildren belonged to an age group approximately between 7 to 11 years of age. In their study 1028 eyes in 514 schoolchildren were screened in the age group ( 7 to 11 years) similar to our study. They found habitual VA of $6 / 6$ in $28.5 \%$ of eyes which is very low as compared to our study (80.42\%). While, $8.99 \%$ of students in his study had a VA of 6/12, which is almost three times higher than our study (2.47\%). Similarly, they measured almost 10 times higher VA of $6 / 24$ in $4.95 \%$ schoolchildren than our study which $(0.44 \%)$. On the other hand, none of the schoolchildren from that age group, from their study had VA of $6 / 60$, while our study showed that in $0.18 \%$ eyes of 
schoolchildren. Vishnuprasad et al., (2017) recently conducted a similar study in different schools of Puducherry, India. They supported our result with rather similar results for the VA of 6/6 (79.8\%), 6/9 (13.8\%), 6/12 (2.47\%), 6/36 (0.4\%) and 6/60 (0.1\%) in schoolchildren. 6/18 VA was slightly higher in their study (2.2\%) in comparison to present study (1.41). On the other hand, almost two times higher result was observed for $6 / 24(1.0 \%)$ for their study. This dissimilarity might be due to a larger sample size and extended age group (10 to 14 years) for their study.

Though, the present study cannot provide definitive prevalence of VI in schoolchildren of Allahabad, due to constrain of limited sample size. But, it does raise scope for further study regarding the prevalence of VI in schoolchildren and its relation to learning. In addition, the present study did not measure uncorrected VA in children who arrived wearing eyeglasses. Which, can be done to see if these children may show some alteration on uncorrected VA testing. A large scale study is required to establish the prevalence of VA in schoolchildren of Allahabad.

\section{Conclusion and recommendation}

Overall majority of schoolchildren in our study belonged to group with good VA. The estimated prevalence of VI in present study shows that almost $20 \%$ of study population is recommended for further evaluation for VA. Habitual VA can be successfully used as a referral criterion after vision screening in schools. It may also help reduce the burden of childhood blindness by early detection of reduced habitual VA. A further study is recommended to compare the prevalence in of VI in urban and rural schoolchildren.

\section{References}

[1] Anstice $\mathrm{N}$ and Thompson B. The measurement of visual acuity in children: an evidence-based update. Clinical and Experimental Optometry. 2013; 97(1): 3-11.

[2] Azizoglu S, Crewther S, Serefhan F, Barutchu A, Göker S and Junghans B. Evidence for the need for vision screening of school children in Turkey. BMC Ophthalmology. 2017; 17(1): 1-14.

[3] Brien Holden Vision Institute (2016). Visual Acuity Web Site. Updated November 11, 2016. Retrieved 08:36, April6, 2018, from:https://brienholdenvisioninstitute.app.box.com/s/li51450sx9q0yjuh563uffewjg2mawvn

[4] Dandona L, Williams JD, Williams BC, Rao GN. Population based assessment of childhood blindness in southern India. Arch Ophthalmol 1998; 116: 545-546.

[5] Dandona R, Dandona L. Refractive error blindness. Bull World Health Organ. 2001; 79:237-243.

[6] District Census Handbook, Allahabad (2011). Census of India 2011. Directorate of Census Operations, Uttar Pradesh. https://www.census2011.co.in/census/district/546-allahabad.html

[7] Education Status Report - Uttar Pradesh (2013). Elementary education. Centre for Education Innovation. WorkingPaper,November2013.Availableat:https://www.educationinnovations.org/sites/default/files/Status\%20o f\%20Elementary\%20Education\%20in\%20Uttar\%20Pradesh.pdf

[8] Gene-Sampedro A, Gene-Morales A, Gené-Morales J, Bueno-Gimeno I and Oliver-Huerta D. Visual Health In The Classroom. Conference Paper. Proceedings of ICERI2016 Conference 14th-16th November 2016, Seville, Spain. Publication at: https://www.researchgate.net/publication/311363145 DOI: 10.21125/iceri.2016.1411

[9] Gilbert C, Foster A. Childhood blindness in the context of VISION 2020 - 'The right to sight.' Bull World Health Org 2001; 79(3): 227-232.

[10] Harvey E, Dobson V and Miller J. Prevalence of High Astigmatism, Eyeglass Wear, and Poor Visual Acuity among Native American Grade School Children. Optometry and Vision Science. 2006; 83(4): 206-212.

[11] He M, Huang W, Zheng Y, et al. Refractive error and visual impairment in school children in rural southern China. Ophthalmology 2007; 114: 374-382.

[12] Marsden J, Stevens S and Ebri A. How to measure distance visual acuity. Community Eye Health. 2014; 27(85): 16. https://www.ncbi.nlm.nih.gov/pmc/articles/PMC4069781/

[13] Maul E, Barroso S, Munoz SR, Spertudo RD, Ellwein LB. The refractive error study in children: Result from La Florida, Chile. Am J Ophthalmol 2000; 129: 445-454.

[14] Ministry of Statistics \& Program Implementation, Press Information Bureau (June 30, 2015). Government of India. Key Indicators of Social Consumption in India on Education Show Continued Gender Gap and Rural Urban Differences. Retrieved June 11, 2018, from http://pib.nic.in/newsite/PrintRelease.aspx?relid=122881 
DOI: $10.21522 /$ TIJPH.2013.06.03.Art013

ISSN: $2520-3134$

[15] Ministry of Statistics \& Program Implementation, Press Information Bureau (June 30, 2015). Government of India. Key Indicators of Social Consumption in India on Education Show Continued Gender Gap and Rural Urban Differences. Retrieved June 11, 2018, from http://pib.nic.in/newsite/PrintRelease.aspx?relid=122881

[16] Mugisha F. School Enrolment among Urban Non-Slum, Slum and Rural Children in Kenya: Is the Urban Advantage Eroding? International Journal of Educational Development. 2006; 26(5): 471-482.

[17] Pastorino N, Penerini Y. Programa de detección de déficit de la agudeza visual en escolares sin patología ocular aparente." Archivos Argentinos de Pediatría (Buenos Aires) 96.4 (1998): 236.

[18] Smith JS. Childhood blindness in India [Editorial]. Eye 1995; 9: 543-544.

[19] Vishnuprasad R, Bazroy J, Madhanraj K, Prashanth H, Singh Z, Samuel A and Muthukumar T. Visual impairment among 10-14-year school children in Puducherry: A cross-sectional study. Journal of Family Medicine and Primary Care, 2017: 6(1): 58-62.

[20] World Health Organization; 2012. Visual impairment and blindness. Fact sheet no. 282 [Internet]. Geneva: Available from: http://www.who.int/mediacentre/factsheets/fs282/en [cited 2016 Jan 17].

[21] Zhao J, Pan X, Sui R, Munoz SR, Sperduto RD, and Ellwein L. Refractive error study in children, results from Shunyi District China. Am J Ophthalmol. 2000; 129: 427-435. 